\title{
Persons Living With Primary Immunodeficiency Act as Citizen Scientists and Launch Prospective Cohort Body Temperature Study
}

Shouling Zhang ${ }^{1,2}$, MD; Tiffany S Henderson ${ }^{3}$, PhD; Christopher Scalchunes ${ }^{3}$, MPA; Kathleen E Sullivan ${ }^{4}, \mathrm{MD}, \mathrm{PhD}$; Artemio M Jongco III ${ }^{2,5,6}, \mathrm{MD}, \mathrm{PhD}, \mathrm{MPH}$

\footnotetext{
${ }^{1}$ Division of Allergy and Immunology, Icahn School of Medicine at Mount Sinai, New York, NY, United States

${ }^{2}$ Department of Pediatrics, Cohen Children's Medical Center, Donald and Barbara Zucker School of Medicine at Hofstra/Northwell, New Hyde Park, NY, United States

${ }^{3}$ Immune Deficiency Foundation, Towson, MD, United States

${ }^{4}$ Division of Allergy and Immunology, Children's Hospital of Philadelphia, Philadelphia, PA, United States

${ }^{5}$ Division of Allergy and Immunology, Donald and Barbara Zucker School of Medicine at Hofstra/Northwell, Great Neck, NY, United States

${ }^{6}$ Center for Health Innovations and Outcomes Research, Feinstein Institute for Medical Research, Manhasset, NY, United States
}

\section{Corresponding Author:}

Artemio M Jongco III, MD, PhD, MPH

Division of Allergy and Immunology

Donald and Barbara Zucker School of Medicine at Hofstra/Northwell

865 Northern Boulevard, Suite 101

Great Neck, NY, 11021

United States

Phone: 1 (516) 6225070

Email: ajongco@northwell.edu

\section{Abstract}

Background: Although fever is considered a sign of infection, many individuals with primary immunodeficiency (PI) anecdotally report a lower-than-normal average body temperature on online forums sponsored by the Immune Deficiency Foundation (IDF). There is limited knowledge about the average body temperature and fever response in PI.

Objective: This study aims to compare median body temperatures between adults with and without PI diagnoses living in the same household and to engage individuals living with PI throughout the research process.

Methods: Patients with PI designed and launched a prospective cohort comparison study as citizen scientists. A multidisciplinary team designed and implemented a patient-informed study with continuous patient-driven input. Median body temperatures were compared between the 2 cohorts using the Mann-Whitney test with Bonferroni correction. The IDF conducted a post-study patient experience survey.

Results: Data from 254 households were analyzed (254/350, 72.6\% participation rate). The PI population was predominantly female $(218 / 254,85.8 \%)$, White $(248 / 254,97.6 \%)$, and with a median age of 49 years. The non-PI population was largely male $(170 / 254,66.9 \%)$, White $(236 / 254,92.9 \%)$, and with a median age of 53 years. Common variable immunodeficiency was the most common PI diagnosis (190/254, 74.8\%). Of the 254 individuals with PI, 123 (48.4\%) reported a lower-than-normal nonsick body temperature, whereas $108(42.5 \%)$ reported a normal (between $97^{\circ} \mathrm{F}$ and $99^{\circ} \mathrm{F}$ ) nonsick body temperature. Among individuals with PI, when infected, $67.7 \%$ (172/254) reported the absence of fever, whereas 19.7\% (50/254) reported a normal fever response. The recorded median body temperature was minimally but statistically significantly higher for patients with PI in the morning. Although $22.4 \%$ (57/254) of patients with PI self-reported illness, a fever of $100.4^{\circ} \mathrm{F}$ or higher was uncommon; $77.2 \%(196 / 254)$ had a normal temperature (between $97^{\circ} \mathrm{F}$ and $99^{\circ} \mathrm{F}$ ), and $16.2 \%\left(41 / 254\right.$ ) had a lower-than-normal temperature (between $95.0^{\circ} \mathrm{F}$ and $96.9^{\circ} \mathrm{F}$ ) when sick. For these sick patients with PI, the median body temperature was minimally but statistically significantly higher for patients in the morning and early evening. Overall, $90.9 \%$ (231/254) of participants would be very likely to participate in future IDF studies, although 94.1\% (239/254) participants had never taken part in previous studies.

Conclusions: To our knowledge, this is the first study to evaluate average body temperature in individuals with PI. Although there were small statistically significant differences in body temperatures between PI and non-PI subjects, the clinical significance 
is unclear and should be interpreted with caution, given the methodological issues associated with our small convenience sample and study design. As PIs are heterogeneous, more research is needed about how the fever response differs among diverse PIs compared with healthy controls. This study highlights that individuals with PI are knowledgeable about their health and can offer unique insights and direction to researchers and clinicians.

(J Participat Med 2020;12(4):e22297) doi: 10.2196/22297

\section{KEYWORDS}

fever; temperature; primary immunodeficiency

\section{Introduction}

\section{Background}

Primary immunodeficiency (PI) diseases represent a class of approximately 450 rare, genetic, and chronic disorders in which there is a defect in the human immune system [1]. To function properly, an immune system must detect and protect against a wide variety of pathogens. It must distinguish between foreign pathogens and their own cells. When any component is absent or dysfunctional, the result is a susceptibility to severe, persistent, unusual, and recurrent infections [1,2].

Normal body temperature is considered an oral measurement of approximately $98.6^{\circ} \mathrm{F}\left(37^{\circ} \mathrm{C}\right)$. Fluctuations in body temperature of $1^{\circ} \mathrm{F}\left(0.6^{\circ} \mathrm{C}\right)$ are known to occur throughout the day depending on the activity level and the time of day. This normal temperature was established in the 19th century; however, more recent studies suggest a lower body temperature [3]. Fever is a proinflammatory response that involves cytokine release, which may include tumor necrosis factor and interleukin-1 [4]. Fever is considered the immune system's response to pathogens to make the body a less favorable environment for infection.

At present, there is a dearth of literature on the average body temperature in persons with PI, and more information on the fever response in PI is needed. Fever is often considered the first sign of infection. Some, but not all, patients with PI can be deficient in generating cytokine responses that may also contribute to pyrogen release and fever response [5]. In PI, a patient may not receive critical antibiotics if a fever is missed; thus, it is essential to understand if a muted fever response exists. Missing an infection in PI may lead to delayed diagnosis or treatment, which can lead to decreased quality of life as well as increased morbidity and mortality for patients [2]. Moreover, it is unclear if and how different types of PI may impact a patient's ability to mount a fever response and baseline thermoregulation. As PIs are heterogeneous and involve different arms of the immune system, the ability of patients with PI to mount a fever response may partly depend on the underlying condition [5]. For example, patients with PI with autoinflammatory conditions, such as Familial Mediterranean Fever or familial cold autoinflammatory syndrome, are characterized by recurrent fever, whereas patients with toll-like receptor defects, such as interleukin-1 receptor-associated kinase 4 deficiency, fail to mount fever in the presence of pyogenic infections [1,5]. More information is needed to understand if individuals with PI have different body temperatures at baseline and when sick so that appropriate medical treatment can be provided in a timely manner.
There has been a recent expansion in the degree of patient involvement occurring in research studies. A recent review of 126 articles by the Patient-Centered Outcomes Research Institute in 2019 highlights how patients are being engaged as early as the study design phase in selecting study outcomes and tailoring interventions to meet patients' needs [6]. Valuable contributions from patients have been reported in research feasibility, acceptability, rigor, and relevance by aligning the needs and concerns of patients and their clinicians. Research is deemed more meaningful for patients, with less burden and with greater adherence to interventions [6]. Efforts to involve patients in the research process are thus considered here.

\section{Objectives}

The purpose of this study is to assess whether patients with PI exhibit lower-than-normal average body temperature compared with individuals without PI. The primary objective is to measure and compare resting body temperature at select time intervals in a cohort of individuals living with PI and unaffected controls who are adult family members without PI living in the same household. The secondary goal is to engage individuals who are affected by PI, including patients, family members, and caregivers throughout the research process as citizen scientists.

\section{Methods}

\section{Overview}

A prospective cohort comparison study was designed to compare 2 populations. This study was designed as a patient-stakeholder collaboration and supported by the Immune Deficiency Foundation (IDF) with oversight by the Advarra institutional review board. No outside funding was received. IDF is composed of patients with PI, along with their family, supporters, and health care professionals who work with the PI community. These stakeholders are involved in every facet of IDF and comprise the leadership, staff, board of trustees, and volunteers that enable the organization to serve the PI community in a comprehensive manner.

IDF improves the diagnosis, treatment, and quality of life of people affected by PI by fostering a community empowered by advocacy, education, and research. IDF provides accurate and timely information for patients and families living with PI and offers valuable resources. IDF sponsors education and outreach efforts for the medical community. In addition, IDF promotes, participates, and conducts research that has helped characterize PI and substantially improve treatment options. Patient needs are addressed by IDF through public policy programs and advocacy at state and federal levels. 


\section{Objectives}

The purpose of this study is to assess whether patients with PI exhibit a lower-than-normal average body temperature compared with non-PI individuals. This study tested the hypothesis that there is no difference in mean body temperature between adults diagnosed with or without PI. The primary objective is to measure and compare resting body temperature at select time intervals in a cohort of individuals living with PI and unaffected controls who are non-PI adult family members living in the same household. All subjects were given the same questionnaires, thermometers, instructions, and schedule for taking their temperatures. The secondary objective is to engage individuals living with PI throughout the entire research process as citizen scientists.

\section{Patient-Led Approach}

This study was a patient-driven study with the participation of patients with PI from its initial inception to completion as citizen scientists. In 2017, several members of the IDF and participants in IDF online forums, such as IDF Friends and PI CONNECT, began a grassroots effort to address concerns of individuals living with PI. Although fever is considered an initial sign of infection, many individuals with PI have been reported to have a lower-than-normal average body temperature. On these online forums, patients with PI reported a temperature less than $100.4^{\circ} \mathrm{F}$ even when other indications of infection were present. Patients with PI expressed an interest in exploring this systematically through a patient-designed research project.

With these initial concerns, IDF participants subsequently approached IDF staff and leadership, who, in turn, contacted members of the IDF medical advisory board and PI researchers. From an online forum, a focus group at the IDF annual meeting was established to discuss concerns of patients with PI. This focus group morphed into a task force that inspired a patient-informed study. Several conference calls followed among patients with PI, IDF staff and leadership, PI clinicians, and PI researchers who expressed interest in designing and implementing a collaborative research project to assess body temperature in patients with PI. The proposed study design underwent several revisions, and a protocol was eventually agreed upon by all key stakeholders and PI representatives. Patient advocates from IDF were on the research team, which included active roles in project design, management, data collection, data analysis, and data reporting through dissemination of findings and manuscript preparation. Clinicians and researchers acted as content experts and advisors to provide input on best practices and rigorous study design, but all stakeholders agreed that the project would defer to the wishes of the patients with PI who were the ultimate drivers of the entire endeavor.

Patients with PI were involved at every step of the process. During study design, patients with PI voiced their interest among focus groups in studying differences in body temperature among healthy participants and participants with PI, which became the aim of the study. Patients with PI shared social media posts and newsletter announcements in subject recruitment and were the key participants in data collection. The materials in the study packets were generated, assembled, and mailed to participants by the IDF staff and volunteers, many of whom live with PI themselves. The study team, IDF staff, and volunteers collaboratively performed data entry, analysis, interpretation, results dissemination, and manuscript preparation. Preliminary research findings were shared with the PI community at IDF conferences and on the web as they became available.

\section{Recruitment}

A total of 350 adults with PI were recruited from IDF rosters, and 1 adult household member without PI was also recruited per patient to serve as a control. The IDF recruited participants through direct email, newsletter announcements, and social media posts among patients with PI. All patients identified as adults aged older than 20 years in the IDF databases received a recruitment email explaining the study and linking participants to a screening questionnaire. A promotional flyer is attached in the supplementary material (Multimedia Appendix 1).

\section{Enrollment}

The initial screening questionnaire, which was used by the IDF for subject selection, surveyed basic demographic and medical information from participants with and without PI. Inclusion criteria included adults with PI aged between 21 and 70 years, who were not acutely ill at study start and who had a willing member of his or her household without PI to serve as a comparator. Exclusion criteria included those aged below 21 years or above 70 years and those unable to take an oral temperature. Informed consent was obtained electronically from both household members of eligible participants before study enrollment. Participants who returned their signed data packets received a US \$20 Amazon coupon per household as an incentive.

\section{Interventions}

Enrolled subjects received a welcome packet with instructions, a thermometer, a data collection booklet, and return envelopes for their booklets. All participants received and used McKesson digital oral thermometers (Model 01-413BGM) to record temperatures 3 times a day for 5 consecutive days for subject convenience. The 5-day study period was chosen based on input from IDF members who believed that this time frame would be acceptable and minimally obtrusive to the community of patients with PI and family members. Each participant took his or her own temperature on arising in the morning, in the early evening, and at bedtime, at approximately the same time of day for each of the 5 days. They recorded their temperatures in a data collection booklet that was returned to the IDF at the study conclusion. Detailed instructions with pictures were provided. Participants were instructed not to drink any hot or cold fluids, smoke, eat, drink, exercise, or perform other activities that may raise or lower temperature readings at least 30 min before taking their temperature. Subjects recorded if an infection was present daily. Of note, researchers could not verify this self-reported status of infection or no infection because of the self-report nature of the study. No collateral information (such as doctor's notes or laboratory testing) to verify this self-report was collected or analyzed in the study. After the study concluded, participants received a follow-up questionnaire to assess their overall study experience as well as their willingness to 
participate in similar patient-driven research in the future with the IDF.

\section{Statistical Analysis}

Descriptive statistics were calculated. Hypothermic temperatures below $95.0^{\circ} \mathrm{F}$ were excluded from the analysis. The median body temperatures were compared between the 2 cohorts using the Mann-Whitney test. We also performed a subgroup analysis comparing the recorded temperatures of patients with PI and controls who self-reported being ill for each time point. Prism 6.0 (GraphPad Software) was used to perform the statistical analyses. Statistical significance was set at a $P$ value $<.05$, and Bonferroni correction for multiple comparisons was applied.

\section{Results}

\section{Participants}

Of the 350 eligible households that were invited, 254 participated in the study $(254 / 350,72.6 \%$ participation rate). The PI and non-PI cohort demographics are summarized in Table 1 . The PI population was predominantly female (218/254, $85.8 \%)$, White $(248 / 254,97.6 \%)$, and with a median age of 49 years. These participant demographics are similar to those of other studies from IDF [7]. The non-PI population was largely male $(170 / 254,66.9 \%)$, White $(236 / 254,92.9 \%)$, and with a median age of 53 years.

Table 1. Participant demographics.

\begin{tabular}{|c|c|c|}
\hline Demographic & $\mathrm{PI}^{\mathrm{a}}$ & Non-PI \\
\hline Age (years), median & 49 & 53 \\
\hline \multicolumn{3}{|l|}{ Age group (PI only; years), n } \\
\hline $21-34$ & 53 & 37 \\
\hline $35-44$ & 52 & 43 \\
\hline $45-54$ & 61 & 64 \\
\hline $55-70$ & 88 & 110 \\
\hline \multicolumn{3}{|l|}{ Sex, $\mathbf{n}$} \\
\hline Male & 35 & 170 \\
\hline Female & 218 & 83 \\
\hline Transgender & 1 & 1 \\
\hline \multicolumn{3}{|l|}{ Race and ethnicity, $n$} \\
\hline American Indian or Alaskan Native & 2 & 1 \\
\hline Asian or Pacific Islander & 0 & 4 \\
\hline Black or African American & 1 & 1 \\
\hline Hispanic or Latino & 5 & 10 \\
\hline White, non-Hispanic & 248 & 236 \\
\hline Two or more races & 5 & 4 \\
\hline
\end{tabular}

${ }^{\mathrm{a} P I}$ : primary immunodeficiency.

\section{PI Diagnoses}

The diagnoses of the PI cohort are summarized in Table 2. Humoral immunodeficiencies predominated with common variable immunodeficiency being the most prevalent (190/254,
$74.8 \%)$. Of the total 254 cases, nonhumoral defects comprised $3(1.2 \%)$ of the diagnoses, including chronic granulomatous disease $1(0.4 \%)$, combined immunodeficiency $1(0.4 \%)$, and complement deficiency $1(0.4 \%)$. 
Table 2. Primary immunodeficiency diagnoses.

\begin{tabular}{ll}
\hline Primary immunodeficiency diagnosis & Participants $(\mathrm{n}=254), \mathrm{n}(\%)$ \\
\hline Common variable immunodeficiency & $190(74.8)$ \\
Hypogammaglobulinemia & $32(12.6)$ \\
Immunoglobulin G subclass deficiency & $12(4.7)$ \\
Selective Immunoglobulin A deficiency & $8(3.1)$ \\
Specific antibody deficiency & $8(3.1)$ \\
Agammaglobulinemia & $1(0.4)$ \\
Chronic granulomatous disease & $1(0.4)$ \\
Combined immunodeficiency & $1(0.4)$ \\
Complement deficiency & $1(0.4)$ \\
\hline
\end{tabular}

\section{Body Temperature Perceptions}

We asked 254 PI respondents about their body temperature perceptions (Table 3). Of the 254 respondents, 123 (48.4\%) PI respondents reported a lower-than-normal nonsick body temperature, whereas $108(42.5 \%)$ reported a normal (between $97^{\circ} \mathrm{F}$ and $99^{\circ} \mathrm{F}$ ) nonsick body temperature. When infected,
$67.7 \%$ (172/254) of the PI respondents reported absence of fever with infection, whereas $19.7 \%$ (50/254) reported a normal fever response with infection. As summarized in Table 3, most participants with PI reported an abnormal nonsick body temperature when well and an absence of fever with infection when sick. These findings underscore the need to better define body temperature in patients with PI.

Table 3. Body temperature perceptions.

\begin{tabular}{ll}
\hline Body temperature perceptions & Frequency, $\mathrm{n}(\%)$ \\
\hline Well condition: Which of the following statements is closest to your experiences with your day-to-day, nonsick, body temperature? \\
My nonsick body temperature is normal (between $\left.97^{\circ} \mathrm{F}-99^{\circ} \mathrm{F}\right)$ & $108(42.5)$ \\
My nonsick body temperature is lower than normal $\left(\right.$ between $\left.95.0^{\circ} \mathrm{F}-96.9^{\circ} \mathrm{F}\right)$ & $123(48.4)$ \\
My nonsick body temperature is higher than normal $\left(\geq 99.1^{\circ} \mathrm{F}\right)$ & $2(0.8)$ \\
Not sure/don't know & $21(8.3)$ \\
Sick condition: When you have an infection, which of the statements below is closest to your experiences? & $50(19.7)$ \\
I have a normal fever response when I get an infection & $172(67.7)$ \\
I do not get a fever when I have an infection & $10(3.9)$ \\
I get a very high fever when I have an infection & $22(8.7)$ \\
Not sure/don't know &
\end{tabular}

\section{Body Temperature Measurements}

The next step of the study focused on measuring the body temperatures of participants with PI to determine whether there were any cohort differences at baseline. During the objective measurement phase of the study, the median body temperatures for each time point on all 5 days and for the week were recorded and are summarized in Table 4. 
Table 4. Objective median body temperatures $\left({ }^{\circ} \mathrm{F}\right)$.

\begin{tabular}{|c|c|c|c|}
\hline Time of day & $\mathrm{PI}^{\mathrm{a}},{ }^{\circ} \mathrm{F}$ (range) & Non-PI, ${ }^{\circ} \mathrm{F}$ (range) & $P$ value \\
\hline \multicolumn{4}{|l|}{ Daily temperatures } \\
\hline Monday morning & $97.5(95.2-100.1)$ & $97.2(95.2-99.4)$ & .03 \\
\hline Monday early evening & $97.8(95.0-99.6)$ & $97.8(95.1-99.3)$ & .81 \\
\hline Monday bedtime & $97.6(95.2-100.4)$ & $97.5(95.2-99.8)$ & .28 \\
\hline Tuesday morning & $97.4(95.3-99.3)$ & $97.2(95.4-98.9)$ & $.002^{\mathrm{b}}$ \\
\hline Tuesday early evening & $97.8(95.0-99.8)$ & $97.7(95.4-99.8)$ & .06 \\
\hline Tuesday bedtime & $97.5(95.4-100.5)$ & $97.4(95.1-100.7)$ & .65 \\
\hline Wednesday morning & $97.5(95.0-99.6)$ & $97.2(95.0-99.6)$ & $.001^{\mathrm{b}}$ \\
\hline Wednesday early evening & $97.8(95.3-99.7)$ & $97.7(95.1-99.8)$ & .40 \\
\hline Wednesday bedtime & $97.5(95.4-99.6)$ & $97.4(95.0-99.6)$ & .67 \\
\hline Thursday morning & $97.4(95.0-99.5)$ & $97.2(95.1-99.0)$ & .06 \\
\hline Thursday early evening & $97.8(95.0-99.6)$ & $97.7(95.0-100.5)$ & .14 \\
\hline Thursday bedtime & $97.4(95.7-99.5)$ & $97.4(95.0-100.6)$ & .32 \\
\hline Friday morning & $97.4(95.2-99.5)$ & $97.1(95.1-101.0)$ & $.001^{\mathrm{b}}$ \\
\hline Friday early evening & $97.7(95.0-99.9)$ & $97.7(95.5-101.2)$ & .71 \\
\hline Friday bedtime & $97.4(95.1-99.9)$ & $97.5(95.0-100.9)$ & .91 \\
\hline \multicolumn{4}{|l|}{ Weekly temperatures } \\
\hline (Monday to Friday) morning & $97.4(95.0-100.1)$ & $97.2(95.0-101.0)$ & $<.001^{\mathrm{c}}$ \\
\hline Early evening & $97.8(95.0-99.9)$ & $97.7(95.0-101.2)$ & .05 \\
\hline Bedtime & $97.5(95.1-100.5)$ & $97.4(95.0-100.9)$ & .37 \\
\hline
\end{tabular}

${ }^{\mathrm{a}} \mathrm{PI}$ : primary immunodeficiency.

${ }^{\mathrm{b}}$ Statistically significant after Bonferroni correction of $P$ value $(0.05 / 15=0.003)$.

${ }^{\mathrm{c}}$ Statistically significant after Bonferroni correction of $P$ value $(0.05 / 3=0.017)$.

\section{Group Comparisons}

Figure 1 graphically shows that compared with controls without PI, individuals with PI had minimally higher median body temperatures in the morning, but not early evening or bedtime, on 3 of 5 days (Tuesday, Wednesday, and Friday) in the top left panel. In the top right panel, Figure 1 further demonstrates that PI subjects had a minimally higher median temperature in the morning during the study.

To examine if these differences in body temperature varied with infection, we compared the temperatures of each cohort during the time of a self-reported illness. Respondents were asked if they perceived themselves to be sick with an infection during each day of the study, but the study design did not permit us to corroborate respondent self-report with an objective assessment such as laboratory testing or physician examination. To assess how subjects' self-reported perception of being sick matched with their recorded temperatures, we tabulated their subjective responses with their recorded temperatures in Tables 5 and 6 for subjects with PI and no PI, respectively. Table 5 shows that $22.4 \%$ (range $20.9 \%-23.6 \%$ ) of PI subjects self-reported being sick at some point during the study period and that fever with temperature $\geq 100.4^{\circ} \mathrm{F}$ only occurred twice. Moreover, $77.2 \%$ (range 64.4\%-87.9\%) reported having a normal temperature (between $97^{\circ} \mathrm{F}$ and $99^{\circ} \mathrm{F}$ ), whereas $16.2 \%$ (range 6.8\%-28.8\%) reported having a lower-than-normal temperature (between $95.0^{\circ} \mathrm{F}$ and $96.9^{\circ} \mathrm{F}$ ) when sick. 
Figure 1. Objective median body temperatures in patients with PI and control nonprimary immunodeficiency household members. Part A depicts all daily objective body temperatures. Statistically significant $P$ value (.003) after Bonferroni correction. Part B depicts all weekly objective body temperatures. Statistically significant $P$ value (.017) after Bonferroni correction. Part C depicts all daily objective body temperatures when they perceive an infection. Statistically significant $P$ value (.003) after Bonferroni correction. Part D depicts all weekly objective body temperatures when sick. Statistically significant $P$ value (.017) after Bonferroni correction. Con: control; PI: primary immunodeficiency.

Figure $1 \mathrm{~A}$

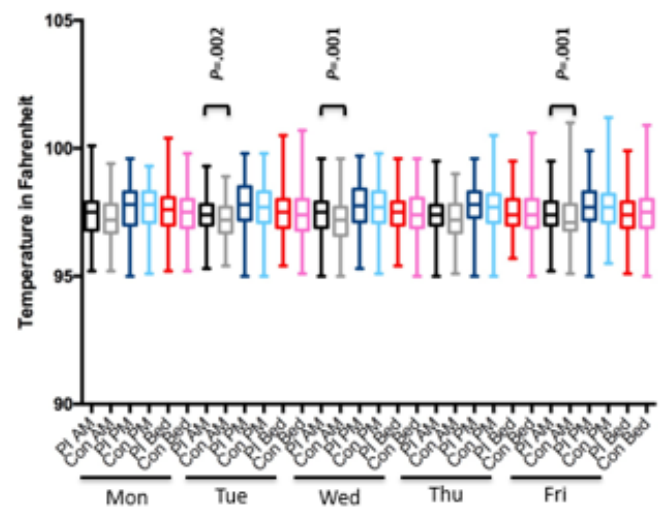

Figure 1C

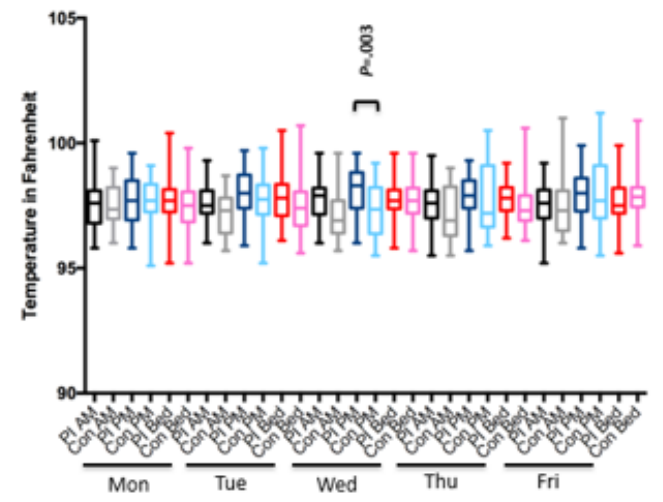

Figure 1B

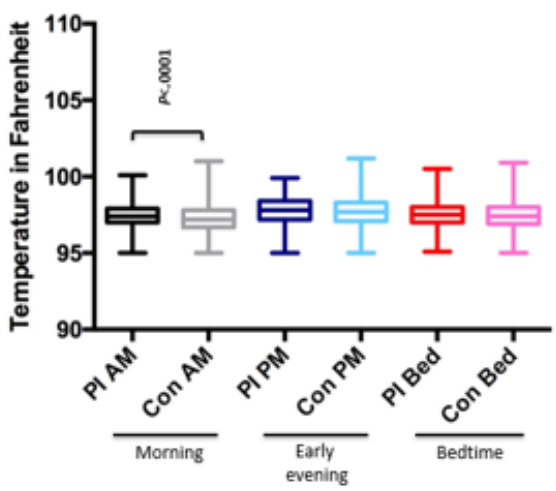

Figure 1D

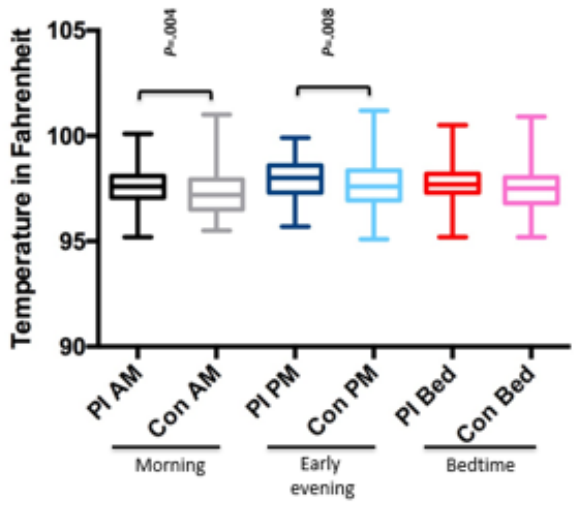


Table 5. Frequency of reported body temperature when sick among primary immunodeficiency subjects.

\begin{tabular}{|c|c|c|c|c|c|c|c|}
\hline \multirow[t]{2}{*}{ Time of day } & \multicolumn{2}{|c|}{ Primary immunodeficiency respondents } & \multicolumn{2}{|c|}{ Temperature $\left({ }^{\circ} \mathrm{F}\right), \mathrm{n}(\%)$} & \multirow[b]{2}{*}{$97.0-99.0$} & \multirow[b]{2}{*}{$95.0-96.9$} & \multirow[b]{2}{*}{$\begin{array}{l}\text { Did not } \\
\text { record }\end{array}$} \\
\hline & $\begin{array}{l}\text { Number of re- } \\
\text { spondents }\end{array}$ & $\begin{array}{l}\text { Percentage of respondents who } \\
\text { reported being sick, } \mathrm{n}(\%)^{\mathrm{a}}\end{array}$ & $\geq 100.4$ & $99.1-100.3$ & & & \\
\hline Monday morning & 59 & $59(23.2)$ & $0(0)$ & $2(3.4)$ & $40(67.8)$ & $17(28.8)$ & $0(0)$ \\
\hline Monday early evening & 59 & $59(23.2)$ & $0(0)$ & $6(10.2)$ & $38(64.4)$ & $15(25.4)$ & $0(0)$ \\
\hline Monday bedtime & 59 & $56(22.0)$ & $1(1.7)$ & $1(1.7)$ & $50(84.7)$ & $4(6.8)$ & $0(0)$ \\
\hline Tuesday morning & 55 & $55(21.7)$ & $0(0)$ & $2(3.6)$ & $44(80.0)$ & $9(16.4)$ & $0(0)$ \\
\hline Tuesday early evening & 55 & $54(21.3)$ & $0(0)$ & $5(9.3)$ & $42(77.8)$ & $7(13.0)$ & $1(1.9)$ \\
\hline Tuesday bedtime & 55 & $53(20.9)$ & $1(1.9)$ & $1(1.9)$ & 39 (73.6) & $12(22.6)$ & $2(3.8)$ \\
\hline Wednesday morning & 60 & $60(23.6)$ & $0(0)$ & $3(5.0)$ & $48(80.0)$ & $9(15.0)$ & $0(0)$ \\
\hline Wednesday early evening & 60 & $58(22.8)$ & $0(0)$ & $8(13.8)$ & $43(74.1)$ & $7(12.1)$ & $2(3.4)$ \\
\hline Wednesday bedtime & 60 & $58(22.8)$ & $0(0)$ & $2(3.4)$ & $48(82.8)$ & $8(13.8)$ & $2(3.4)$ \\
\hline Thursday morning & 58 & $58(22.8)$ & $0(0)$ & $2(3.4)$ & $43(74.1)$ & $13(22.4)$ & $0(0)$ \\
\hline Thursday early evening & 58 & $55(21.7)$ & $0(0)$ & $3(5.5)$ & $48(87.3)$ & $4(7.3)$ & $3(5.5)$ \\
\hline Thursday bedtime & 58 & $58(22.8)$ & $0(0)$ & $1(1.7)$ & $51(87.9)$ & $6(10.3)$ & $0(0)$ \\
\hline Friday morning & 58 & $58(22.8)$ & $0(0)$ & $1(1.7)$ & 45 (77.6) & $11(19.0)$ & $1(1.7)$ \\
\hline Friday early evening & 58 & $57(22.4)$ & $0(0)$ & $5(8.8)$ & $42(73.7)$ & $8(14.0)$ & $2(3.5)$ \\
\hline Friday bedtime & 58 & $55(21.7)$ & $0(0)$ & $4(7.3)$ & $40(72.7)$ & $9(16.4)$ & $4(7.3)$ \\
\hline $\operatorname{Mean}^{\mathrm{b}}(\%)$ & $\mathrm{N} / \mathrm{A}^{\mathrm{c}}$ & 22.4 & 0.2 & 5.4 & 77.2 & 16.2 & 2.0 \\
\hline
\end{tabular}

${ }^{\mathrm{a}}$ Percent sick is based on 254 respondents. For each temperature, percentage is based on the number of sick.

${ }^{\mathrm{b}}$ Means are the average of all percentages per column.

${ }^{\mathrm{c}} \mathrm{N} / \mathrm{A}$ : not applicable.

Table 6 shows that $6.3 \%$ (range $3.9 \%-8.7 \%$ ) of subjects without PI self-reported being sick at some point during the study period and that fever only occurred 7 times. Furthermore, $60.9 \%$ (range

$42.1 \%-80.0 \%$ ) reported having a normal temperature, whereas $30.8 \%$ (range $10.0 \%-53.8 \%$ ) reported having a lower-than-normal temperature when sick. 
Table 6. Frequency of reported body temperature when sick among subjects with no primary immunodeficiency.

\begin{tabular}{|c|c|c|c|c|c|c|c|}
\hline \multirow[t]{2}{*}{ Time of day } & \multicolumn{2}{|c|}{ Respondents with no primary immunodeficiency } & \multicolumn{2}{|c|}{ Temperature $\left({ }^{\circ} \mathrm{F}\right), \mathrm{n}(\%)$} & \multirow[b]{2}{*}{$97.0-99.0$} & \multirow[b]{2}{*}{$95.0-96.9$} & \multirow[b]{2}{*}{$\begin{array}{l}\text { Did not } \\
\text { record }\end{array}$} \\
\hline & $\begin{array}{l}\text { Number of re- } \\
\text { spondents }\end{array}$ & $\begin{array}{l}\text { Percentage of respondents who } \\
\text { reported being sick, } \mathrm{n}(\%)^{\mathrm{a}}\end{array}$ & $\geq 100.4$ & $99.1-100.3$ & & & \\
\hline Monday morning & 17 & $17(6.7)$ & $0(0)$ & $0(0)$ & $13(76.5)$ & $4(23.5)$ & $0(0)$ \\
\hline Monday early evening & 17 & $17(6.7)$ & $0(0)$ & $1(6.9)$ & $13(76.5)$ & $3(17.6)$ & $0(0)$ \\
\hline Monday bedtime & 17 & $17(6.7)$ & $0(0)$ & $1(5.9)$ & $11(64.7)$ & $5(29.4)$ & $0(0)$ \\
\hline Tuesday morning & 22 & $22(8.7)$ & $0(0)$ & $0(0)$ & $13(59.1)$ & $9(40.9)$ & $0(0)$ \\
\hline Tuesday early evening & 22 & $22(8.7)$ & $0(0)$ & $2(9.1)$ & $16(72.7)$ & $4(18.2)$ & $0(0)$ \\
\hline Tuesday bedtime & 22 & $21(8.3)$ & $1(4.8)$ & $0(0)$ & $11(52.4)$ & $9(42.9)$ & $1(4.8)$ \\
\hline Wednesday morning & 19 & $19(7.5)$ & $0(0)$ & $1(5.3)$ & $8(42.1)$ & $10(52.6)$ & $0(0)$ \\
\hline Wednesday early evening & 19 & $18(7.1)$ & $0(0)$ & $1(5.6)$ & $10(55.6)$ & $7(38.9)$ & $1(5.6)$ \\
\hline Wednesday bedtime & 19 & $19(7.5)$ & $0(0)$ & $2(10.5)$ & $13(68.4)$ & $4(21.1)$ & $0(0)$ \\
\hline Thursday morning & 13 & $13(5.1)$ & $0(0)$ & $0(0)$ & $6(46.2)$ & $7(53.8)$ & $0(0)$ \\
\hline Thursday early evening & 13 & $13(5.1)$ & $1(7.7)$ & $2(15.4)$ & $6(46.2)$ & $4(30.8)$ & $0(0)$ \\
\hline Thursday bedtime & 13 & $11(4.3)$ & $1(9.1)$ & $0(0)$ & $7(63.6)$ & $3(27.3)$ & $2(18.2)$ \\
\hline Friday morning & 11 & $11(4.3)$ & $1(9.1)$ & $0(0)$ & $6(54.5)$ & $4(36.4)$ & $0(0)$ \\
\hline Friday early evening & 11 & $11(4.3)$ & $2(18.2)$ & $1(9.1)$ & $6(54.5)$ & $2(18.2)$ & $0(0)$ \\
\hline Friday bedtime & 11 & $10(3.9)$ & $1(10.0)$ & $0(0)$ & $8(80.0)$ & $1(10.0)$ & $0(0)$ \\
\hline $\operatorname{Mean}^{\mathrm{b}}(\%)$ & $N / A^{c}$ & 6.3 & 3.9 & 4.5 & 60.9 & 30.8 & 1.9 \\
\hline
\end{tabular}

${ }^{\text {a }}$ Percent sick is based on 254 respondents. For each temperature, percentage is based on the number that is sick.

${ }^{\mathrm{b}}$ Means are the average of all percentages per column.

${ }^{\mathrm{c}} \mathrm{N} / \mathrm{A}$ : not applicable.

For those patients and controls who reported being sick, the median temperatures at each time of day are tabulated in Table 7.

Figure 1 shows that individuals with PI who self-reported being sick had minimally higher median body temperatures in the early evening midweek on Wednesday in the bottom left panel.

The bottom right panel in Figure 1 further demonstrates that the same PI subjects had minimally higher median temperatures in the morning and early evening in the bottom panel during the study. Overall, we found the majority of participants, regardless of PI status, had normal measured temperatures during times of reported infection, and that fevers were rare. 
Table 7. Objective median body temperatures $\left({ }^{\circ} \mathrm{F}\right)$ when sick.

\begin{tabular}{|c|c|c|c|}
\hline Time of day & $\mathrm{PI}^{\mathrm{a}},{ }^{\circ} \mathrm{F}$ (range) & Non-PI, ${ }^{\circ} \mathrm{F}$ (range) & $P$ value \\
\hline \multicolumn{4}{|l|}{ Daily temperatures } \\
\hline Monday morning & $97.6(95.8-100.1)$ & $97.3(96.0-99.0)$ & .99 \\
\hline Monday early evening & $97.7(95.8-99.6)$ & $97.7(95.1-99.1)$ & .87 \\
\hline Monday bedtime & $97.7(95.2-100.4)$ & $97.5(95.2-99.8)$ & .17 \\
\hline Tuesday morning & $97.5(96.0-99.3)$ & $97.3(95.7-98.7)$ & .09 \\
\hline Tuesday early evening & $98.0(95.9-99.7)$ & $97.8(95.2-99.8)$ & .14 \\
\hline Tuesday bedtime & $97.8(96.1-100.5)$ & $97.4(95.6-100.7)$ & .11 \\
\hline Wednesday morning & $97.9(96.0-99.6)$ & $96.9(95.7-99.6)$ & .01 \\
\hline Wednesday early evening & $98.3(96.0-99.6)$ & $97.4(95.5-99.2)$ & $.003^{\mathrm{b}}$ \\
\hline Wednesday bedtime & $97.7(95.8-99.6)$ & $97.7(95.7-99.6)$ & .54 \\
\hline Thursday morning & $97.6(95.5-99.5)$ & $96.9(95.5-99.0)$ & .29 \\
\hline Thursday early evening & $97.9(95.7-99.3)$ & $97.2(95.9-100.5)$ & .18 \\
\hline Thursday bedtime & $97.8(96.2-99.2)$ & $97.3(96.1-100.6)$ & .10 \\
\hline Friday morning & $97.6(95.2-99.2)$ & $97.3(96.0-101.0)$ & .48 \\
\hline Friday early evening & $98.0(95.8-99.9)$ & $97.7(95.5-101.2)$ & .92 \\
\hline Friday bedtime & $97.5(95.6-99.9)$ & $97.9(95.9-100.9)$ & .39 \\
\hline \multicolumn{4}{|l|}{ Weekly temperatures } \\
\hline (Monday-Friday) morning & $97.6(95.2-100.1)$ & $97.2(95.5-101.0)$ & $.004^{\mathrm{c}}$ \\
\hline Early evening & $98.0(95.7-99.9)$ & $97.6(95.1-101.2)$ & $.008^{\mathrm{c}}$ \\
\hline Bedtime & $97.7(95.2-100.5)$ & $97.5(95.2-100.9)$ & .04 \\
\hline
\end{tabular}

${ }^{\mathrm{a}} \mathrm{PI}$ : primary immunodeficiency.

${ }^{\mathrm{b}}$ Statistically significant with Bonferroni adjusted $P$ value $(0.05 / 15=.003)$.

${ }^{\mathrm{c}}$ Statistically significant with Bonferroni adjusted $P$ value $(0.05 / 3=.017)$.

\section{Poststudy Patient Experience Survey}

The research team developed a postassessment survey to obtain participant feedback because this was the first time that IDF used such a citizen science approach to research. A total of 67 participants $(67 / 254,26.4 \%$ participation rate) completed the poststudy assessment. Of the 67 participants, a total of $65(97 \%)$ respondents were participants with PI. Overall, the respondents appeared to have a positive experience with this research endeavor: (1) 94\% (63/67) reported that it would be very likely for them to read a summary report of the study when posted on IDF's website; (2) $81 \%$ (54/67) reported it would be very likely that they would read a published peer-reviewed article; and (3) $91 \%(61 / 67)$ indicated that it would also be very likely that they would participate in future IDF research studies, although $93 \%$ (62/67) of participants had never taken part in previous IDF research studies. Overall, participants were enthusiastic about the research process that was participant-driven at every step. Members of the PI community, including those not directly involved in the research, were very engaged when preliminary study results were presented at IDF meetings. Members of the research team and other key stakeholders anecdotally reported witnessing and participating in many interesting conversations about the findings at various IDF events and online forums.

Highlighting the overwhelming positive response to the project and the expectation that this work would be shared outside the IDF community are among the driving forces behind publishing this manuscript.

\section{Discussion}

\section{Principal Findings}

Although discrepancies between subjective and objective core body temperatures in chronic disease have been reported previously, limited literature exists on average body temperature in persons with PI [3,8]. Hamilos et al [8] monitored continuous 24-hour body temperature recordings of 7 patients with chronic fatigue syndrome (CFS) and compared them against 3 sets of age-, sex-, and weight-matched cohorts (normal controls, subjects with seasonal allergy, and subjects with major depression). Despite frequent self-reports of subnormal body temperature and low-grade fever, CFS subjects were found to have normal core body temperatures [8]. To our knowledge, our study is the first to evaluate average body temperature in PI subjects, thus improving our understanding of another chronic disease and addressing an important knowledge gap.

Interestingly, our study did not corroborate the beliefs of patients with PI and their caregivers regarding their temperatures when 
ill and in their usual state of health. Many caregivers and persons living with PI believe that patients with PI run lower-than-normal sick and nonsick temperatures. Of the 254 participants, $123(48.4 \%)$ participants subjectively reported this, whereas $108(42.5 \%)$ reported normal nonsick temperatures. Of the 254 participants, $172(67.7 \%)$ respondents subjectively reported an absence of fever during infection, whereas 50 $(19.7 \%)$ reported fever with infections. Our findings suggest that patients with PI appear to have minimally higher morning temperatures compared with controls even after adjusting for multiple comparisons [9]. However, these results need to be interpreted with caution, given our small sample size and methodological study design issues. Less than $25.0 \%$ of the subjects with PI self-reported being sick at some point during the study period. Of these, the majority $(196 / 254,77.2 \%)$ reported a normal temperature, $(42 / 254,16.4 \%)$ had a lower-than-normal temperature, and $(1 / 254,0.2 \%)$ had a fever. Less than $7.0 \%$ of the subjects with no PI self-reported being sick at some point during the study period. Of these, most $(155 / 254,60.9 \%)$ reported a normal temperature, whereas $(78 / 254,30.8 \%)$ had a lower-than-normal temperature and $(10 / 254,3.9 \%)$ had a fever. Our findings suggest that patients with PI may have minimally higher morning and early evening median temperatures compared with healthy controls when subjects self-report being sick. Such small differences fall within normal variation for daily temperatures and are likely not clinically meaningful.

Although we found statistically significant differences in body temperatures between subjects with PI and no PI when they self-reported being sick or healthy, the clinical significance of such small differences is unclear and should be interpreted cautiously. Previous studies have shown variations in thermoregulation among the general population. An observational cohort study of 35,488 patients (mean age 52.9 years, $64 \%$ women, $41 \%$ non-Whites) from a large academic hospital from 2009 to 2014 showed that of 243,506 outpatient temperature measurements, the mean temperature was $36.6^{\circ} \mathrm{C}$ $\left(97.9^{\circ} \mathrm{F}\right)$ with a $95 \% \mathrm{CI}$ of $35.7^{\circ} \mathrm{C}-37.3^{\circ} \mathrm{C}\left(96.3^{\circ} \mathrm{F}-99.1^{\circ} \mathrm{F}\right.$; [10]). Older individuals were the coolest $\left(-0.021^{\circ} \mathrm{C}\right.$ for every decade; $P<.001)$, and African American women were warmer than White men $\left(+0.052^{\circ} \mathrm{C} ; P<.001\right)$. Several comorbidities were linked to lower temperatures, including hypothyroidism $\left(-0.013^{\circ} \mathrm{C}\right.$; $P=.01)$ as well as higher temperatures including cancer $(+0.020$; $P<.001)$ and BMI $\left(+0.002\right.$ per $\left.\mathrm{kg} / \mathrm{m}^{2} ; P<.001\right)$. Measured factors explained only $8.2 \%$ of individual temperature variation, whereas unexplained temperature variation was a significant predictor of subsequent mortality: controlling for all measured factors, an increase of $0.149^{\circ} \mathrm{C}$ was linked to $8.4 \%$ higher 1-year mortality $(P=.02 ;[10])$. Possible explanations for higher median body temperatures in patients with PI, which should be considered in future studies, include differences in subclinical infection/inflammation, hormone levels, thyroid function, comorbidities including malignancy, dietary intake and activity level, and body composition.

As many of our subject with PI were women of childbearing age, future studies are needed to elucidate the potential roles of hormonal changes and the menstrual cycle on body temperature, given this major difference in sex between our study and control populations. A study of core temperatures in young, healthy women with regular menstrual cycles and baseline fluctuations of $>0.5^{\circ} \mathrm{C}$ in basal core temperature during luteal and follicular phases revealed consistently higher temperatures in the luteal phase than in the follicular phase [11]. The small variation in temperature between PI and non-PI participants in this study may be related to hormonal effects causing fluctuating body temperatures in menstruating females, so future studies of body temperature differences should account for menstrual cycles, especially if large sex differences in study populations exist, as is the case in this study.

It is also possible that the fever response fundamentally differs between subjects with and without PI, and future studies are needed to elucidate the involved immunocytes and cytokine milieu of fever in patients with PI [12]. PIs are diverse, and the arms of the immune system that are affected in these heterogeneous conditions likely differentially impact thermoregulation and the ability to mount a fever response. Future studies are needed to assess whether this difference in fever response is a manifestation of immune dysregulation among patients with PI.

\section{Study Strengths}

Our study had several strengths, including the prospective study design, and continued collaboration from the community from initial inception to study completion. This commitment from the PI community enabled the study to be done in partnership with participants at all stages of the endeavor, which facilitated high participation and engagement. The experience of working with citizen scientists was positive for collaborators as well. There was a conscious decision by all stakeholders that we would always err on following the wishes of the participants who were the driving force behind the project. The innovative, patient-driven, and team-based approach to this study was well received by the PI community, as seen in the poststudy assessment as well as collaborators. The research team and the IDF staff will continue to build upon this experience by adopting this paradigm of actively engaging persons living with PI at all stages of research endeavors in future projects.

\section{Limitations}

However, we acknowledge that our study has several limitations, such as differences in household settings and individual differences in taking a temperature. As participants were not observed directly, we cannot exclude the possibility that temperatures may have been taken inconsistently or in slightly different household settings with different thermostat settings. Providing the same thermometer and instructions partially mitigates this concern. In addition, we acknowledge that our analyses do not control for daily medications (eg, antipyretics), activity, or subclinical illness symptoms. Notably, our study did not assess the impact of immunomodulator use, such as steroids or biologics, which can interfere with fever response. Infections were self-reported by patients and not verified by providers or objective collateral information, which limits data interpretation. A major limitation of this study is that infection was not defined explicitly to participants during the study period, which vastly limits the ability to draw definitive conclusions about body temperature differences during times of illness in 
this study. Because these limitations potentially seriously compromise the scientific integrity and validity of our study, all stakeholders participated in extensive discussions with content experts in study design, statistics, and immunology, regarding these weaknesses during the inception and planning stages. Ultimately, stakeholders jointly decided to err on the side of following what patients with PI stated that they could and were willing to do for the study.

Our study was also not designed to assess the impact of the wearing off effect that some patients with humoral immunodeficiency on monthly intravenous immunoglobulin $\mathrm{G}$ (IgG) infusion can experience before their next dose [7,13,14]. The wearing off effect is associated with decreased treatment efficacy, increased infection susceptibility, and diminished quality of life. This effect should be considered since a 2003 IDF study consisting of 1186 subjects showed that 308 (25.96\%) of patients with PI reported feeling wearing off occasionally, whereas 498 (41.99\%) reported wearing off as a typical experience of their therapy. Patients experiencing a wearing off effect can benefit with more frequent dosing (every 3 vs 4 weeks) or with switching to a subcutaneous route [15]. Future studies are needed to determine how body temperature among patients with PI might be influenced by this phenomenon and whether the $\mathrm{IgG}$ replacement route plays a role.

In addition, our study used a convenience sample without randomization. We cannot exclude the possibility of participation bias among different types of patients with PI with respect to diagnosis or other demographic factors. Subjects were not well balanced in the type of PI or gender; thus, our findings need to be interpreted cautiously. However, as humoral immunodeficiencies account for most PIs, with common variable immune deficiency being the most common, it is not surprising that our cohort is skewed this way. Our study design cannot assess the potential effect of hormones, sex, or age on the outcomes of interest. Future studies specifically including men, children, young adults, and older adults with PI and appropriate controls that are matched by age and sex are needed.

Online forums pose unique challenges for patient-led studies. There is a unique non-face-to-face platform for interactions and the possibility of unpredictable security issues that may complicate informed consent. An interdisciplinary team, including team members with expertise in computing and ethics, may be important for troubleshooting such difficulties. Special considerations such as whether a forum should be facilitated or moderated, an informed consent process that is not done in person, language use, and data analysis are all factors considered in previous studies of online forums [16]. Considering how the start of this study began on an online forum, it is important to pay attention to these factors in future studies.

\section{Poststudy Survey}

Our poststudy questionnaire encouraged feedback from the PI community after study completion. An important caveat is that the questionnaire only had a $26.4 \%(67 / 254)$ participation rate. Nonetheless, this rate is comparable with that reported in other studies conducted by IDF. Although many respondents were first-time participants in IDF research, the patient experience was largely positive. Participants were engaged in the study, and $91 \%(61 / 67)$ reported that they would most likely participate in future IDF research studies. Most participants were also interested in reading study results, which we are enthusiastic to share. Closing the loop with a poststudy questionnaire highlights the patient-driven approach of this study and underscores the investment of the target population in research that directly benefits their community.

\section{Conclusions}

This study highlights that individuals with PI are knowledgeable about their conditions and can offer unique insights and direction to researchers. Similarly, this study also demonstrates that collaboration with patient advocacy groups may facilitate high participation among the target population, giving new meaning to the concept of patient-centered and patient-driven research for future studies. We acknowledge that our study has several methodological shortcomings and did not clearly resolve the original research question posed by the PI community. Nonetheless, this endeavor demonstrates that the PI community has the desire and ability to conceive, design, and implement citizen science when given the support to do so.

\section{Acknowledgments}

The authors would like to thank the subjects with PI and their families for conceiving, planning, and participating at all stages of this collaborative endeavor. The authors would also like to thank Dr Joud Hajjar for insightful critiques of the early versions of the manuscript.

\section{Conflicts of Interest}

None declared.

\section{Multimedia Appendix 1}

Promotional flyer for the Immune Deficiency Foundation fever study. [DOCX File, 482 KB-Multimedia Appendix 1]

\section{References}


1. Bousfiha A, Jeddane L, Picard C, Al-Herz W, Ailal F, Chatila T, et al. Human inborn errors of immunity: 2019 update of the IUIS phenotypical classification. J Clin Immunol 2020 Jan;40(1):66-81 [FREE Full text] [doi: 10.1007/s10875-020-00758-x] [Medline: $\underline{32048120]}$

2. Ballow M, Blaese RM, Bonilla FA, Fleisher T, Holland S, Ochs HD, et al. In: Buckley RH, editor. Immune Deficiency Foundation Diagnostic and Clinical Care Guidelines for Primary Immunodeficiency Diseases. Towson, MD: Immune Deficiency Foundation; 2015.

3. Gomolin IH, Aung MM, Wolf-Klein G, Auerbach C. Older is colder: temperature range and variation in older people. J Am Geriatr Soc 2005 Dec;53(12):2170-2172. [doi: 10.1111/j.1532-5415.2005.00500.x] [Medline: 16398904]

4. Kluger MJ. Fever: role of pyrogens and cryogens. Physiol Rev 1991 Jan;71(1):93-127 [FREE Full text] [doi: 10.1152/physrev.1991.71.1.93] [Medline: 1986393]

5. Raje N, Dinakar C. Overview of immunodeficiency disorders. Immunol Allergy Clin North Am 2015 Nov;35(4):599-623 [FREE Full text] [doi: 10.1016/j.iac.2015.07.001] [Medline: 26454309]

6. Forsythe LP, Carman KL, Szydlowski V, Fayish L, Davidson L, Hickam DH, et al. Patient engagement in research: early findings from the patient-centered outcomes research institute. Health Aff (Millwood) 2019 Mar;38(3):359-367. [doi: 10.1377/hlthaff.2018.05067] [Medline: 30830822]

7. Hajjar J, Kutac C, Rider NL, Seeborg FO, Scalchunes C, Orange J. Fatigue and the wear-off effect in adult patients with common variable immunodeficiency. Clin Exp Immunol 2018 Dec;194(3):327-338 [FREE Full text] [doi: 10.1111/cei.13210] [Medline: $\underline{30168848}$ ]

8. Hamilos DL, Nutter D, Gershtenson J, Redmond DP, Clementi JD, Schmaling KB, et al. Core body temperature is normal in chronic fatigue syndrome. Biol Psychiatry 1998 Feb 15;43(4):293-302. [doi: 10.1016/s0006-3223(97)83214-3] [Medline: 9513740]

9. Dunn OJ. Multiple comparisons among means. J Am Stat Assoc 1961 Mar;56(293):52-64. [doi: $\underline{10.1080 / 01621459.1961 .10482090]}$

10. Obermeyer Z, Samra JK, Mullainathan S. Individual differences in normal body temperature: longitudinal big data analysis of patient records. Br Med J 2017 Dec 13;359:j5468 [FREE Full text] [doi: 10.1136/bmj.j5468] [Medline: 29237616]

11. Nagashima K. Thermoregulation and menstrual cycle. Temperature (Austin) 2015;2(3):320-321 [FREE Full text] [doi: 10.1080/23328940.2015.1066926] [Medline: 27227035]

12. Evans SS, Repasky EA, Fisher DT. Fever and the thermal regulation of immunity: the immune system feels the heat. Nat Rev Immunol 2015 Jun;15(6):335-349 [FREE Full text] [doi: 10.1038/nri3843] [Medline: 25976513]

13. Berger M. Subcutaneous administration of IgG. Immunol Allergy Clin North Am 2008 Nov;28(4):779-802, viii. [doi: 10.1016/j.iac.2008.07.002] [Medline: 18940574]

14. Rojavin MA, Hubsch A, Lawo J. Quantitative evidence of wear-off effect at the end of the intravenous IGG (IVIG) dosing cycle in primary immunodeficiency. J Clin Immunol 2016 Apr;36(3):210-219 [FREE Full text] [doi:

10.1007/s10875-016-0243-z] [Medline: 26910102]

15. Treatment Experiences and Preferences of Patients With Primary Immune Deficiency Diseases: First National Survey. Immune Deficiency Foundation. 2003. URL: https://primaryimmune.org/sites/default/files/publications/ Treatment-Experiences-and-Preferences-of-Patients-with-Primary-Immune-Deficiency-Disease-First-National-Survey-2002_1. pdf [accessed 2020-04-01]

16. Im E, Chee W. Practical guidelines for qualitative research using online forums. Comput Inform Nurs 2012 Nov;30(11):604-611 [FREE Full text] [doi: 10.1097/NXN.0b013e318266cade] [Medline: 22918135]
Abbreviations
CFS: chronic fatigue syndrome
IDF: Immune Deficiency Foundation
PI: primary immunodeficiency

Edited by S Woods; submitted 07.07.20; peer-reviewed by B Narayan; comments to author 24.08.20; revised version received 25.09.20;
accepted 20.10.20; published 30.11.20
Please cite as:
Zhang S, Henderson TS, Scalchunes C, Sullivan KE, Jongco III AM
Persons Living With Primary Immunodeficiency Act as Citizen Scientists and Launch Prospective Cohort Body Temperature Study
J Participat Med 2020;12(4):e22297
URL: $\underline{\text { http://jopm.jmir.org/2020/4/e22297/ }}$
doi: $10.2196 / 22297$
PMID: $\underline{3252341}$


(C) Shouling Zhang, Tiffany S Henderson, Christopher Scalchunes, Kathleen E Sullivan, Artemio M. Jongco III. Originally published in Journal of Participatory Medicine (http://jopm.jmir.org), 30.11.2020. This is an open-access article distributed under the terms of the Creative Commons Attribution License (https://creativecommons.org/licenses/by/4.0/), which permits unrestricted use, distribution, and reproduction in any medium, provided the original work, first published in Journal of Participatory Medicine, is properly cited. The complete bibliographic information, a link to the original publication on http://jopm.jmir.org, as well as this copyright and license information must be included. 